\title{
The Metabolism Analysis of Urban Building by 4d-GIS - A Useful Method for New-type Urbanization Planning in China
}

\author{
Chang Chen ${ }^{1,2,3, *}$, Feng Shi ${ }^{2,3}$, Keijiro Okuoka ${ }^{1}$, Hiroki Tanikawa ${ }^{1}$ \\ ${ }^{1}$ Graduate School of Environmental Studies, Nagoya University, Japan \\ ${ }^{2}$ Institute of Science and Technology for Development of Shandong, China \\ ${ }^{3}$ Shandong Academy of Science, China
}

Copyright $\mathrm{O} 2016$ by authors, all rights reserved. Authors agree that this article remains permanently open access under the terms of the Creative Commons Attribution License 4.0 International License

\begin{abstract}
A large number of buildings have been built for the urbanization of China in recent decades. A huge amount of material input in construction leads to the problem of high consumption, high emission and the waste of buildings in the future. In the urbanization context, one way to solve the environmental problems is new-type urbanization, which means focusing on resource-conserving cities and environment-friendly cities. This paper presents an analytical method for urban building metabolism by using four-dimensional Geographical Information Systems (4d-GIS). In this research, we establish the database of buildings by calculating floor area, material intensity, material flow and demolition curve, based on the study area (Ezhou City in Hubei Province, China), and present the city by aerial view of 4d-GIS image. 4D-GIS could be applied in material analysis of urban material metabolism and spatial data analysis. Moreover, it can also quantify and visualize urban metabolism and provide references and solutions for urban planning, which is new-type urbanization.
\end{abstract}

Keywords 4d-GIS, Material Intensity, Material Stock Analysis, Sustainable Development

\section{Introduction}

The economic growth in china hadn't been stagnated by sub-prime crisis because the government enacted 10 measures and invested 4 trillion China yuans to stimulate the economy by the end of 2010. All of these measures stimulated domestic demands, boosted domestic economy and raised the Investment-to-GDP ratio to $76.7 \%$ in 2013 [1]. In Fig. 1 [2], the sustained rapid growth for floor space shows that a huge number of buildings have been built in recent years because of the urbanization in China. The problems of high emission, high consumption and air pollution have emerged. In this situation, sustainable development which plans to balance the economic development and environmental protection is necessary. The new pattern urbanization focusing on resource-conserving city and environment-friendly city is a significant part of sustainable development, which has drawn the attention of academic. Many experts and scholars have analyzed the urban sustainable development from the standpoint of urban metabolism.

In 1965, Wolman [3] suggested the concept of urban metabolism that regarded city as an eco-system. In his paper, city system is a metabolic process. Water supply, sewage treatment and air pollution are the most serious problems of urban metabolism. Ayres et al. [4] introduced "The principle of material balance" in 1969 to observe the material flow of national economy. As a result material flow analysis has become an important method to study urban metabolism. In 1971, Rappaport [5] extended the connotation of urban metabolism to 4 major components including resource consumption, energy flow, capital accumulation and waste excretion within urban socio-economic system.

Urban metabolism is concerned with materials flow in a socio-economic system and also the impact of the process on ecological environment. Therefore, material flow analysis has become the main research method to study social metabolism and to explore how to calculate the material flow within the urban system [6]. In the 1990s, with the rising of the industrial ecology concept, material flow analysis had been widely applied. A number of researchers applied it to analyze the condition of natural resources and material flow [7].The marked feature of urbanization and industrialization is the dramatic changes in land use type and socio-economic metabolism [8]. Thus, the study of metabolic response of land use change became one of the priorities in metabolism research. In addition, resources consumption, material stock and waste emission of land use change could all be incorporated into the metabolism model and in turn establish 
the new model on the basis of land use. [9]

The principal purpose of this paper is presenting the analysis of urban building metabolism by using 4d-GIS. $4 \mathrm{~d}-\mathrm{GIS}$ is based on 3d-GIS with time series database.3d-GIS is a geographic information system based on data structure, spatial query and model analysis in 3D data model .Its function is analysis and operation of space objects in 3D space, having a unique ability to manage complex spatial objects and spatial analysis. The technology has been penetrated into ever field, such as land management, electric power, traffic, water conservation, fire protection, telecom [10]. In 2009, Tanikawa and Hashimoto [11] did a spatial material stock analysis by using 4d-GIS show the change of material stock overtime. 4d-GIS is consists of 3d-GIS and timeline. The urban material stock, material input and material output can be estimated by using 4d-GIS to show the life cycle of buildings in city. The urban material stock, material input and material output can be estimated by using $4 d-G I S$ to show the life cycle of buildings in city.

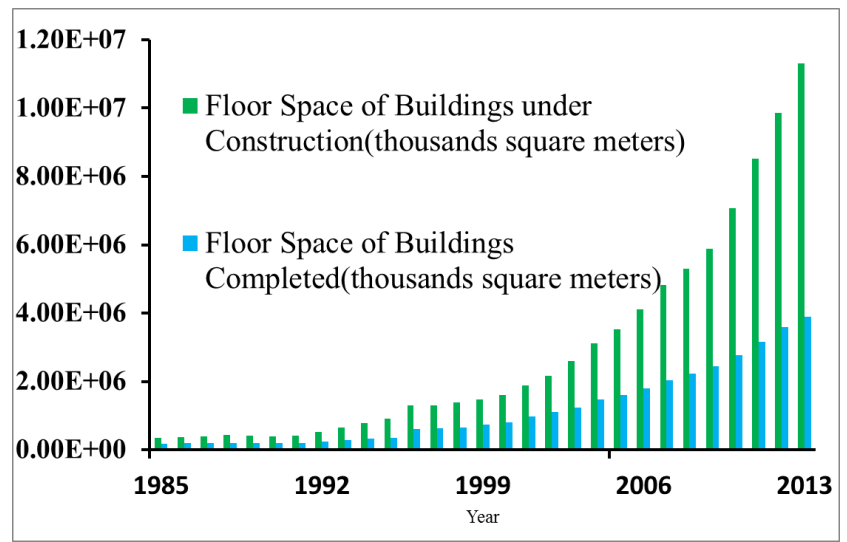

Figure 1. Floor space of building under construction and completed

\section{Methodology}

The calculation of material stock and material flow is based on the calculation equations and the various statistical data.

\subsection{Calculation Equations of Material Stock}

Calculation method for material stock:

$$
M S_{b(i)}^{y}=\sum\left(F A_{b}^{y} \times I_{b(i)}^{y}\right)
$$

Where $M S_{b(i)}^{y}$ is the amount of material $i$ stocked in the building in year $y ; F A_{b}^{y}$ means the total area of building in year $y$ based on statistical data. $I_{r}^{y}$ Indicates the intensity of material $i$ in building in year $t$. [11] [12] [13] [14]

\subsection{Database Establishment}

In this research, urban center of Ezhou city is chosen as the research area. The total floor area of all buildings should be estimated for the material stock calculation. Figure 2[15] shows the GIS database of research area, which is established by the CAD drawing and aerial maps. All the building shapes are traced in Arc-GIS from the maps and CAD drawing to establish the database. Then, based on the database, the total floor area can be calculated by adding the attributes of structure and floors according to the field survey data and combining them to vectorlized maps.

\subsection{Material Intensity of Buildings}

Material intensity, resembling a unit of the calculation of material, shows the material input per unit area. As shown in Table 1 and Table 2[16], the value is based on the average value of samples collected from buildings in different area.

\subsection{Demolition curve}

Demolition curve, a significant part of urban metabolism, indicating the buildings from existence to disappearance.

The demolition rate $(\mathrm{N})$ of an $\mathrm{x}$ yeas old building is calculated by a logistic curve:

$$
\mathrm{N}=\mathrm{K} /(1+\mathrm{a} * \exp (-\mathrm{bx}))
$$

Where $\mathrm{N}$ means demolition rate; $\mathrm{x}$ means age of a building; $\mathrm{K}$ means carrying capacity, and $\mathrm{a}, \mathrm{b}$ are function parameters. $\mathrm{K}$ is the limitation of building demolition rate. When the demolition rate $(\mathrm{N})$ equals to $50 \%$ (the ratio of remaining to demolish buildings is 50:50), $\mathrm{x}$ should equal to the average life span of buildings. (The formula is based on Komatsu, Y. Statistical study on lifetime of Japanese wooden houses [17]. As shown in table 3, the demolition curve is calculated by the change of buildings numbers with the times. The remaining rate is the ratio of remaining buildings to buildings built in different years $(1970,1980,1995,2005,2013$ in this paper). The remaining rate of $x$ years old buildings can be calculated. The demolition rate of $x$ year's old buildings can be calculated by one minus remaining rate. The parameters $\mathrm{K}$, a, $\mathrm{b}$ of equations are obtained by combining the data $(\mathrm{x}, \mathrm{N})$ and equation of demolition rate and fitting the irregular curve.

In this paper, the life span can be calculated by the equation when the $\mathrm{N}$ equals to $50 \%$ and the demolish rate in future can also be estimated by the equation. Nevertheless, insufficient data in study area limits the calculation of parameters in 1995, 2005, 2013. In addition, due to the transformation of the old city, the difference between the average numbers of buildings built in 1970-2005 and those built in 2006-2013 is obvious. Therefore, the value for average life span and demolition rate are set in reference to previous articles [11] [12] [13] [14] [18].

The material flow analysis using 4d-GIS improves understanding of urban metabolism and can be used not only for the buildings, but also for other infrastructure such as roadways, railways and sewers. It is useful for the urban plan and helpful for reducing urban waste in the long-term.

4D-GIS material flow analysis could provide theory foundation for city planning. It is explained by using the 
simulated planning scenario below.

Ezhou City is expanding. The construction of new city district cause population migration. As old city center where adjacent to lake, study area will transform from residential area to ecological region in the future. According to projected demolition rate of buildings from 2013 to 2020, a square meters of residence are demolished as a result $b$ ton of construction waste are generated. The housing area of Ezhou is 40 square meters per capita (Data from Ezhou Statistics Bureau). C people are expected to move to new city district and will require D square meters of housing area. E square

\section{CAD drawing}
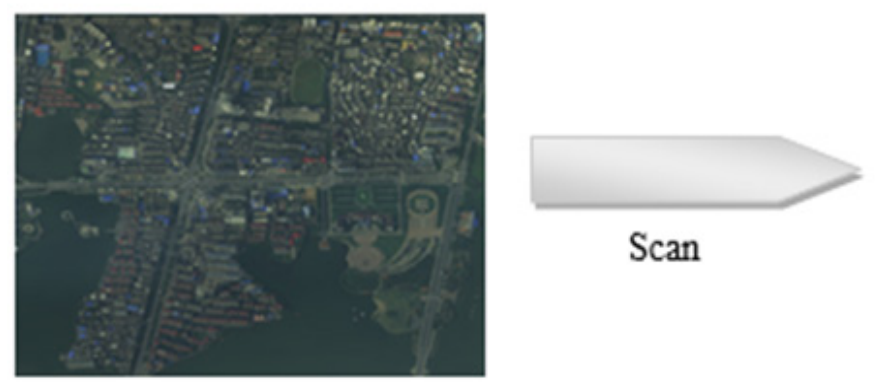

\section{Aerial maps}
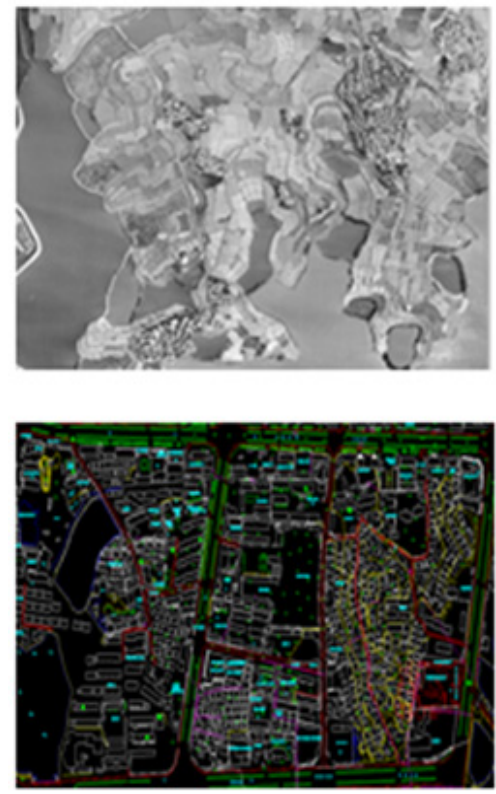

meters of public facilities will be constructed on the original location of destructed buildings. Using calculation in conjunction with table 2 , we could find out that $f$ ton of cement, $\mathrm{g}$ ton of steel, $\mathrm{h}$ ton of woods and $\mathrm{i}$ ton of bricks are required. Combing detailed planning scheme and 4D-GIS material flow analysis, the amount of construction waste and material consumption of new construction could be calculated. The results provide theory foundation for planning of waste disposal and building material production and avoid issues such as excess production of building materials and lack of waste disposal capacity etc.

\section{GIS}
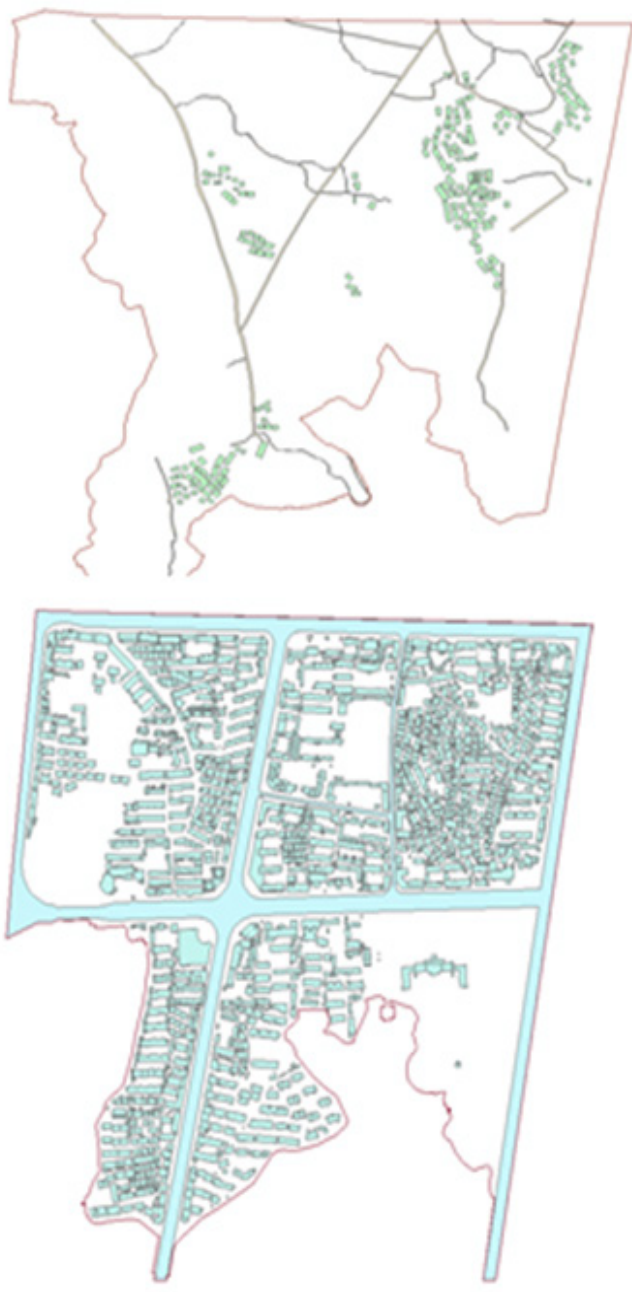

Figure 2. Establish GIS Data

Table 1. Material intensity of public building

\begin{tabular}{|c|c|c|c|c|c|c|}
\hline Residential building $\left(\mathrm{kg} / \mathrm{m}^{2}\right)$ & & & cement & steel & wood & brick \\
\hline \multirow{2}{*}{$\begin{array}{c}\text { High-rise building } \\
(\text { floors } \geq 10)\end{array}$} & & & & & & \\
\cline { 2 - 7 } & RC & & 233 & 30 & 56 & 66 \\
\hline & & & & & & \\
\hline \multirow{2}{*}{$\begin{array}{c}\text { Multi-story building and bungalow } \\
(\text { floors }<10)\end{array}$} & Brick-concrete & & 165 & 26 & 21 & 587 \\
\cline { 2 - 7 } & & & & & & 23 \\
\cline { 2 - 7 }
\end{tabular}




\subsection{Material Input and Output}

The calculations of material input and output are used by comparative eliminating in GIS. As shown in Figure 3, shapes of two neighboring point have been compared and eliminated. After removing the overlapped shapes, the remaining shapes are divided into two parts. The shapes in earlier time are demolished buildings, and the rest are new buildings. The figure indicates the change of buildings intuitively. Thus, the material input and output can be calculated by the material stock of the demolished buildings and new buildings.

\section{Result and Discussion}

Some useful data of study area have been calculated in the research and helpful for material flow analysis.

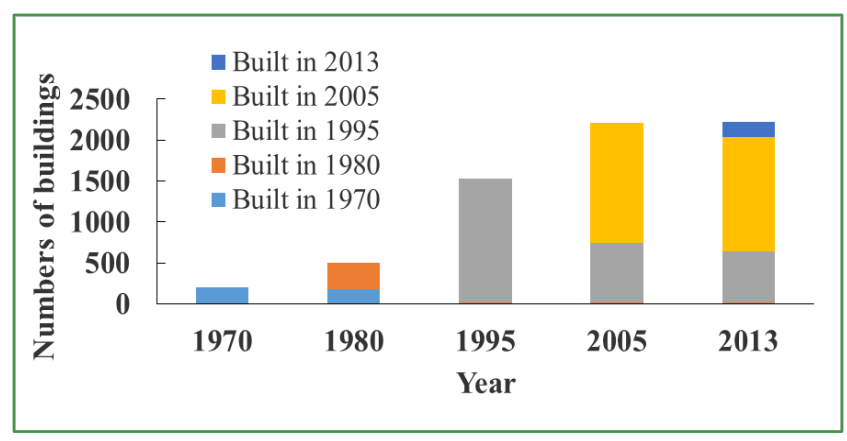

Figure 3. Numbers of buildings in study area

Figure 3 and figure 8 show the change of buildings with time in research area by using 4d-GIS data. Figure 3 shows the specific values and the change of building numbers in different times. Figure 8 presents the regional appearance in a very visual way.

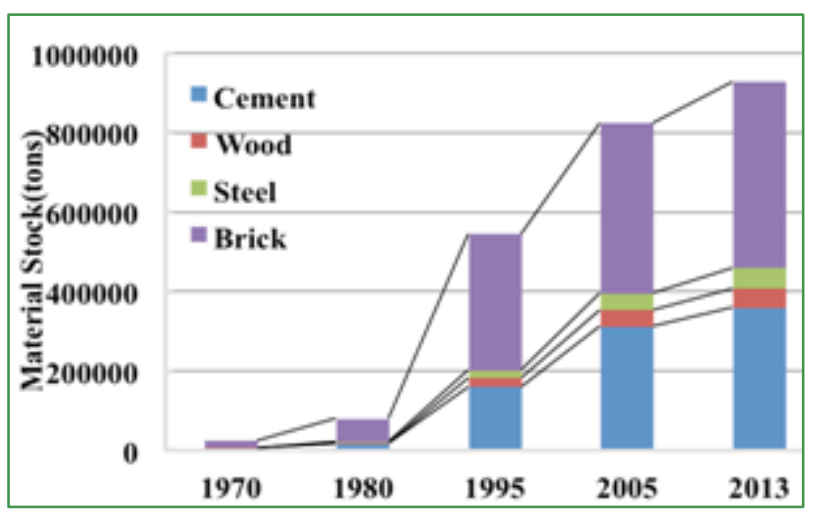

Figure 4. Material stock of study area

Figure 4 shows the amount of material stock from 1970 to 2013 in study area. Material stock is divided into different types by building materials. Due to the amount of the building rocketed from 204 in 1970 to 2222 in 2103 and the changes of structure, material stock increased about 37 times in 43 years from 24750 tons in 1970 to 927552 tons in
2013. The largest change is in 1980-1995 because of the reform and openness.

The material stock density of buildings in study area is $15184 \mathrm{tons} / \mathrm{km}^{2}$ in 1970 , and 569050 tons $/ \mathrm{km}^{2}$ in 2004. The results are much larger than the study area in UK (The material stock density of study area is 418000 tons $/ \mathrm{km}^{2}$ in 2004 including buildings, roads and railways [11]. Such a big difference is caused by the aggregation of high-rise residential buildings in urban center.

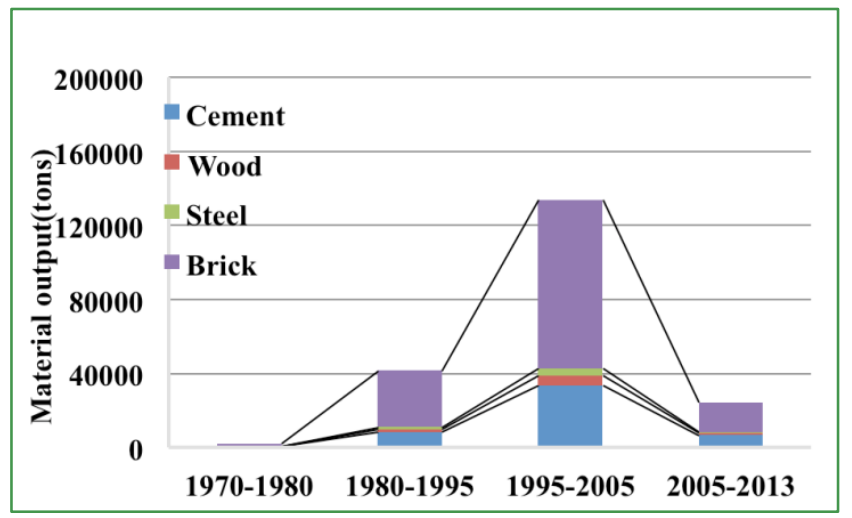

Figure 5. Material of demolition buildings (Material output of buildings)

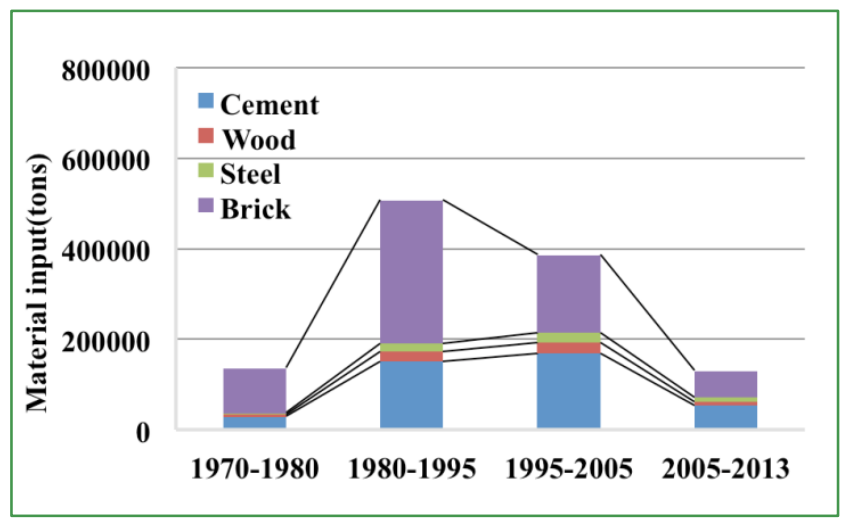

Figure 6. Material of new construction buildings (Material input of buildings)

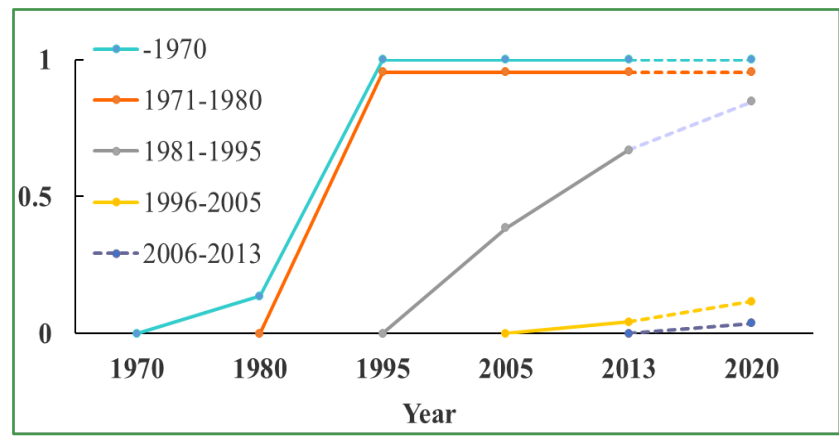

Figure 7. Demolition curve of study area

As shown in Figure 5 and Figure 6, the most significant growth of material input in 1980-1995 is due to the development in China by the reform and openness and the low rates before 1980. The material input of buildings is limited to the land space after 1995 . 
The urban planning is considering both the new building construction and the old city transformation. The material input of building is much larger than output in the study area for past 40 years. The wastes of buildings have been created mostly from 1995 to 2015 , which are mainly caused by the large number of material input and output in 1980-2005. As shown in Figure 8, no more land can be used for construction after the massive construction in 1980-1995. The structure and shape of some buildings in the same places are changed in 1995-2005. The transformation of old city leads to the demolition and new construction of buildings. In addition, to improve land use efficiency, more high-rise buildings (RC type) have been built in1995-2005, which leads to the increase of steel and cement use.

As shown in Fig.8,demolision curve changes a great deal by the time due to the change of buildings structure and the urban planning(transformation of old city).

4D-GIS material flow analysis could provide theory foundation for city planning. It is explained by using the simulated planning scenario below.

Ezhou city is expanding. The construction of new city district causes population migration. As the downtown by the lake, research area will transform from residential area to ecological region in the future as shown in Fig 9. According to projected demolition rate of buildings from 2013 to 2020, $220955 \mathrm{~m}^{2}$ of residence are demolished resulting in 12799 ton of construction waste. The housing area of Ezhou city is $40 \mathrm{~m}^{2}$ per capita (Data from Ezhou Statistics Bureau). 5524 people are expected to move to new city district and will require $220955 \mathrm{~m}^{2} \mathrm{~s}$ of residential area. $50000 \mathrm{~m}^{2}$ of public buildings will be constructed on the original location of destructed buildings. Through the calculation in conjunction with Table 2, we could find out that 1082.5 tons of cement, 147.5 tons of steel, 212.5 tons of woods and 2310 tons of bricks are required for public building construction. Combing detailed planning scheme and 4D-GIS material flow analysis, the amount of construction waste and material consumption of new construction could be calculated. The results provide theory foundation for planning of waste disposal and building material production and avoid issues such as excess production of building materials and lack of waste disposal capacity etc.
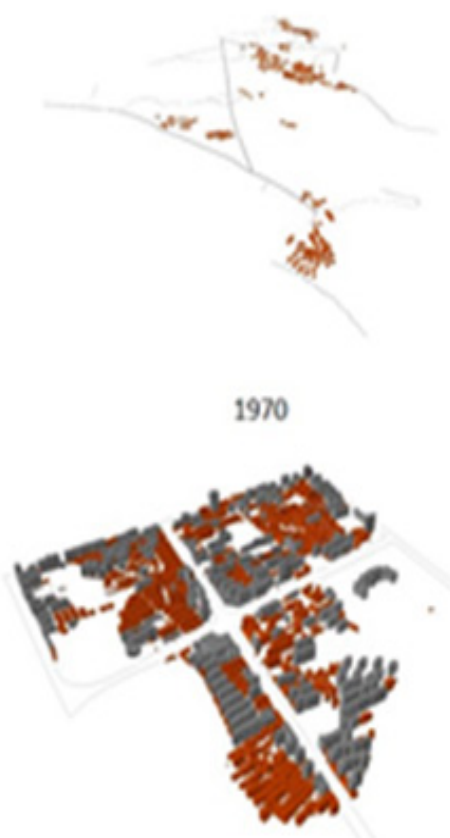

2005

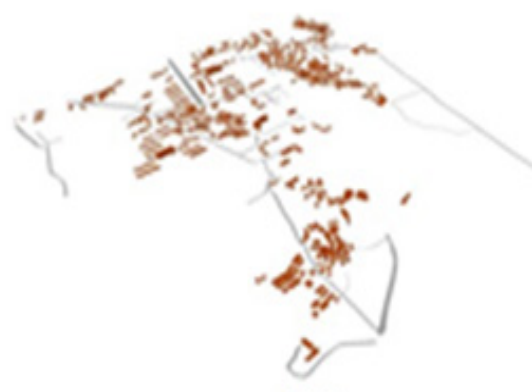

1980

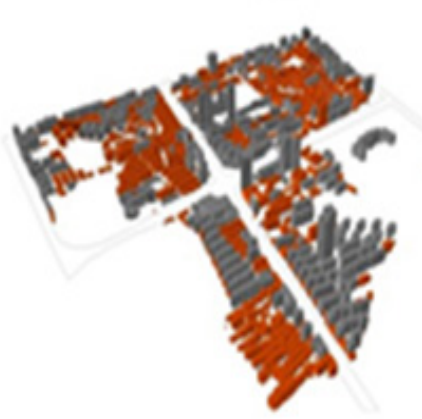

2013

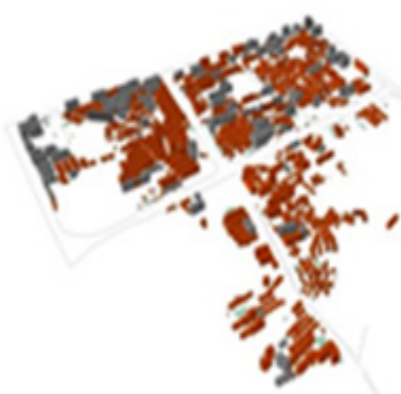

1995

Figure 8. Aerial view of 4d-GIS data base for study area in Ezhou City

Table 2. Material intensity of public building

\begin{tabular}{|c|c|c|c|c|c|}
\hline Public building $\left(\mathrm{kg} / \mathrm{m}^{2}\right)$ & & cement & steel & wood & brick \\
\hline \multirow{2}{*}{ Structure } & $\mathrm{RC}$ & 242 & 31 & 55 & 278 \\
\hline & Brick- concrete & 191 & 28 & 30 & 646 \\
\hline
\end{tabular}


Table 3. The parameters of Logistic curve which is calculated by the 4d-GIS data for Ezhou in Hubei, China

\begin{tabular}{|c|c|c|c|c|c|c|}
\hline \multirow{2}{*}{$\mathrm{N}=\mathrm{K} /(1+\mathrm{a} * \exp (-\mathrm{bx}))$} & \multicolumn{5}{|c|}{ Period of built year } & \multirow{2}{*}{$\begin{array}{c}\text { Average life } \\
\text { span(year) }\end{array}$} \\
\hline & -1970 & $1970-1980$ & 1980-1995 & $1995-2005$ & $2005-2015$ & \\
\hline Number of samples & 204 & 328 & 1512 & 1466 & 190 & \\
\hline K & 1 & 0.95 & N.S. & N.S. & N.S. & \\
\hline A & 510342000 & $6.55 \mathrm{E}+17$ & - & - & - & \\
\hline B & 1.82 & 5.11 & - & - & - & \\
\hline $\begin{array}{c}E^{\wedge} 2 \text { (sum of squares } \\
\text { due to error) }\end{array}$ & 0 & 0 & - & - & - & \\
\hline \multirow[t]{2}{*}{ Life Span $x^{\prime}\left(N^{\prime}=50 \%\right)$} & 11 & 8 & - & - & - & 9.5 \\
\hline & & & \multicolumn{4}{|c|}{ N.S.: no significance by small sample } \\
\hline
\end{tabular}

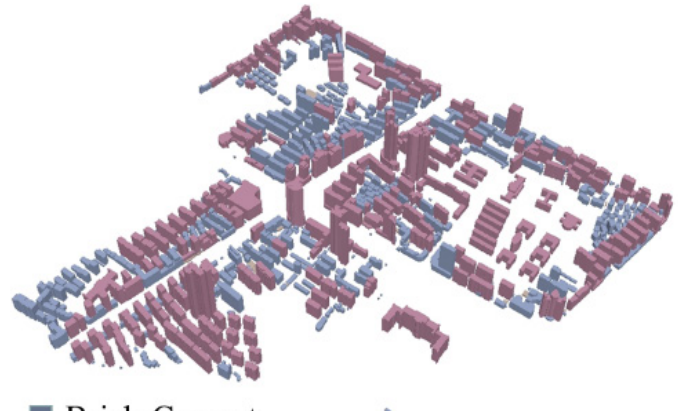

Brick-Cement

2013

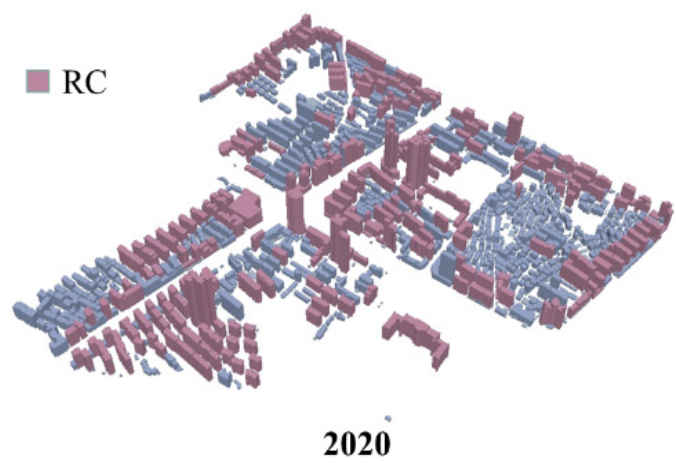

Figure 9. Simulation diagram in 2020

As shown in Figure 5, the proportion of cement and steel using for the new building construction increased as a result of the change in building structure. Combining Figure 1 with Figure 10, the growth of construction and change of structure also increased the output of cement and steel to meet the demand of materials.

Combining the amount of cement as shown in Fig.6 and the $\mathrm{CO}_{2}$ emission of cement production [19], about 403402tons cement have been used for new building construction from1970 to 2013 in study area and the $\mathrm{CO}_{2}$ output from the cement production has reached 263575 tons during the period.

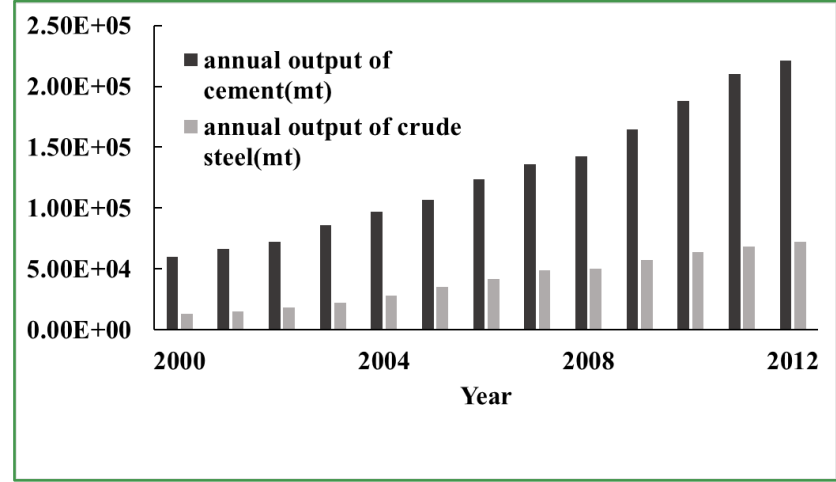

Figure 10. Annual output of cement and steel of China

\section{Conclusions}

This paper proposes an analytical method for urban building metabolism using 4d-GIS. By applied in material analysis of material metabolism and spatial data analysis, it can quantify and visualize urban metabolism and offer some help for the implementation of new-type urbanization.

As a medium sized city, the construction development of Ezhou city is years of 1980-2015. This is correlated to city transformation. After that the amount of buildings in center district had almost no change. The buildings built after 2005 have longer life-span. This phenomenon may exist in other medium and small cities. The life time extension of buildings reduces the materials input of new construction buildings, which have facilitated the development of resource-conserving cities.

The structure of building has transformed from brick and concrete to reinforced concrete after 1995. Thus the construction material has also changed and the cement usage has increased. The mass production of cement brought high emission. In order to increase environmental friendliness for environment-friendly city, the construction material can switch to eco-friendly materials such as gypsum etc. 
The results of material stock, material input and output of buildings indicate the material consumption of urban building construction over time. However, buildings are occasionally refurbished by people. The material flow of refurbishment could not be calculated without data. It is hard to find the change of shapes of the refurbishment in GIS data hence it might flaw in the value of material input and output. In addition, some building materials such as sand, stone and glass are not considered because of data deficiency. Some results may be incomprehensive or inaccurate. However, the research idea provides great prospect for new-type urbanization with supplement and optimization.

\section{Acknowledgements}

This paper was supported by the Taishan Scholar Program of Shandong Province, China and Science and Technology Planning Project of Shandong Province, China (Grant No.2014GGC01070)

\section{REFERENCES}

[1] Ren X Q. Under the background of financial crisis to strengthen infrastructure construction feasibility analysis. 2009(2)1-2. In Chinese]

[2] China Year Book (available at: http://data.stats.gov.cn).19852013[In Chinese]

[3] Wolman A. The metabolism of cities [J]. Scientilic American, 1965, 213(3): 179-188.

[4] Ayres R U, Kneese AV. Production, consumption and externalities. American Economic Review, 59(3):282-297. 1969.

[5] Rappaport R A The flow of energy in an agricultural society. Scientific American, 224(3):117-133. 1971.

[6] F Kowalski M. Society's metabolism: On the Childhood and adolescence of arising conceptual star// Redclift M, Woodgate G R. The international hand book of environmental sociology. Cheltenham, UK: Edward El-gar. 1997.

[7] Schmidt B, leek F. A universal ecological measure. Fresenius Environmental Bulletin, 2(1):407-412. 1993.

[8] Krausmann F, Haber H. The process of industrialization from the perspective of energetic metabolism: Socioeconomic energy flows in Austria 1830-1995. Ecological Economics, 41(2): 177-201. 2002.

[9] Song T. Review and prospects of urban metabolism research. Progress in geography, 2013(11), 1650-1661 [In Chinese]

[10] K. Iwamura, K. Muro, N. Ishimaru, and M. Fukushima, "4D-GIS (4 dimensional GIS) as spatial-temporal data mining platform and its application to management and monitoring of large-scale infrastructures", 2011 IEEE International Conference on Spatial Data Mining and Geographical Knowledge Services (ICSDM 2011), 2011, pp.38-43, doi: 10.1109/ICSDM.2011.5969001.

[11] Tanikawa, H. and Hashimoto, S.: Urban stock over time: spatial material stock analysis using 4d-GIS, Building research\& Information, 37(5-6), pp. 483-502. 2009.

[12] Huang T. Study on the Materials Demand and Environmental Impact Associated with Infrastructure Development in China [D] Nagoya, Department of Environmental Engineering and Architecture Graduate School of Environmental Studies, Nagoya University.2011

[13] T Huang, F Shi, H Tanikawa, J Fei, J Han. Material demand and environmental impact of buildings construction and demolition in China based on dynamic material flow analysis. Resources, Conservation \& Recycling, 2013, 72, 91-101. IF 2.889 .

[14] F. Shi., T. Huang, H. Tanikawa, J. Han, S. Hashimoto, and Y. Moriguchi, Toward a Low Carbon Dematerialization Society: Measuring the Materials Demand and $\mathrm{CO} 2$ Emissions of Building and Transport Infrastructure Construction in China, Journal of Industrial Ecology,16(4), 493-505, 2012.08 IF 2.276

[15] Ezhou urban planning bureau, Hubei province, China

[16] Wang, "Housing construction valuation handbook",1996

[17] Komatsu, Y. statistical study on lifetime of Japanese wooden houses. Journal of Architectural Institute of Japan, 373, 57-62. 1987. [In Japanese]

[18] Zheng L C. A Multi-scale Analysis of Material Stock in Buildings and Transportation Infrastructure [D] Nagoya, Department of Environmental Engineering and Architecture Graduate School of Environmental Studies, Nagoya University.2013

[19] Wang L. The calculation of $\mathrm{CO}_{2}$ emissions cement production of enterprise. China Cement, 2009(11):21-22. (In Chinese)

[20] F Kowalski. Society's metabolism. Journal of Industrial Ecology, 2(1):61-78. 1998.

[21] Chen X Q, Zhao T T, Guo Y Q,etal.2003.Material input and output analysis of Chinese economy system. Acta Scicen-tiarum Naturalum Universitis Pekinesis, 71(4):538-547.

[22] Bergsdal, H., Brattebo, H., Bohne, R. and Mueller, D. Dynamic material flow analysis 2007.

[23] Norway's dwelling stock. Building Research \& Information, 35(5), 557-570.

[24] Ezhou social undertakings development present situation analysis in 2013(online available at: http://ez.hb.stats.cn/info /2014/C1219296.htm)[In Chinese]

[25] You F, Study on Carbon Emissions of Urban Building Metabolism Based on LCCE Model [D]Beijing, University of Chinese Academy of Sciences.2010. 